\title{
The correlation between full moon and admission volume for penetrating injuries at a major trauma centre in South Africa
}

\author{
VY Kong, ${ }^{1,2}$ iD AA Keizer, ${ }^{3}$ (iD MM Donovan, ${ }^{4}$ (D) RD Weale, ${ }^{5}$ (iD NS Rajaretnam, ${ }^{6}$ (D) JL Bruce, ${ }^{2}$ (i) A Elsabagh, ${ }^{7}$ (iD) DL Clarke ${ }^{1,2}$ (D) \\ ${ }^{1}$ Department of Surgery, University of the Witwatersrand, South Africa \\ ${ }^{2}$ Department of Surgery, University of KwaZulu-Natal, South Africa \\ ${ }^{3}$ Department of Surgery, Alrijne Hospital, The Netherlands \\ ${ }^{4}$ Department of Surgery, Stanford University School of Medicine, United States of America \\ ${ }^{5}$ Department of Surgery, North West Deanery, United Kingdom \\ ${ }^{6}$ Department of Surgery, Waikato Hospital, New Zealand \\ ${ }^{7}$ Department of Surgery, Flinders Medical Centre, Australia
}

Corresponding author, email: victorywkong@yahoo.com

Background: The possible effect of full moon on admission volume of trauma centres is a well-mentioned phenomenon that has been perpetuated worldwide. We aimed to review the correlation between full moon and admission volume and to interrogate any possible relationship on admission for penetrating trauma.

Methods: A retrospective study from 2012 to 2018 at Pietermaritzburg Metropolitan Trauma Service (PMTS), South Africa.

Results: A total of 8722 patients were admitted. Eighty-three per cent ( 7 242/8 722) were male and the mean age was 29 years. The total number of days during the study period was 1953 , 66 of which were 'full moon' (FM) days and 1887 were 'non-full moon' (NFM) days. There was no significant difference between gender or age distribution. The mean number of admissions per day on FM days compared with NFM days was not significant $(4.1 \mathrm{vs} 4.5, p=0.583)$. A total of 3332 patients with penetrating trauma were admitted. This constituted $42 \%(113 / 271)$ of admission on FM days and 38\% (3 219) on NFM days, which is not statistically significant ( $p=0.229)$. Subgroup analysis did not demonstrate any significant difference between the number of stab wounds - 28\% (77/113) vs 25\% (2 124/3 219) - or gunshot wounds - 13\% (16/113) vs 12\% (990/3 219) - between FM and NFM days.

Conclusion: The correlation between full moon and trauma admission is unfound in our setting. The perpetuating notion that 'it must be full moon tonight' is likely to be an urban myth with no scientific evidence for such a claim.

Keywords: emergency medicine, trauma, epidemiology, full moon, lunar cycle

\section{Introduction}

Trauma in South Africa has been aptly described as a 'malignant epidemic' and represents a significant burden on the limited resources for all trauma centres throughout the country. ${ }^{1}$ Worldwide, there appears to be a common notion in many emergency departments (ED) that the effect of the full moon is somehow correlated to admission volume and busyness of the centre. ${ }^{2}$ The effect of lunar cycles on human behaviour was thought to be related to alteration of biological rhythm. ${ }^{3}$ Numerous theories have been postulated, including gravitational pull of the moon that may affect the function of the pineal gland. These were thought to alter human behaviour that includes disinhibition, increased aggression and self-destructive behaviour. ${ }^{3-5}$ For decades, the exact relationship between lunar phases and human behaviour has remained somewhat controversial and confusing, as numerous studies have attempted to correlate these with mixed results. ${ }^{2}$ Several studies from the United States in the 1990s consistently demonstrated that lunar phase has no effect on trauma and emergency admissions. ${ }^{2,6,7}$ Although the expression that 'it must be full moon tonight' is mostly made in jest, it remains one of the common urban myths and is a widely held folklore in ED. ${ }^{2,3}$ In a survey published by Danzl in 1987 using the modified belief in lunar effects (BILE) scale, $80 \%$ of ED nurses and $64 \%$ of the ED physicians believe that the moon affects patients. ${ }^{7} \mathrm{Of}$ these nurses, 92\% find lunar shifts particularly stressful and indicated lunar pay differentials were warranted. ${ }^{7}$

At the primary author's (VYK) institution (PMTS), there appears to be persistent conviction, in particular for admissions related to penetrating trauma from interpersonal violence, that the volume may be related to the full moon. Importantly, this phenomenon has never been studied in South Africa. This study was designed to review the correlation between full moon and admission volume and to interrogate any possible relationship on admission for penetrating trauma presented to a major trauma centre in a developing world setting.

\section{Materials and methods}

\section{Clinical setting}

This was a retrospective study conducted at the Pietermaritzburg Metropolitan Trauma Service (PMTS), 
Pietermaritzburg, South Africa. The PMTS is one of the largest academic trauma centres in western KwaZulu-Natal (KZN) province and is one of the main teaching hospitals affiliated to Nelson Mandela School of Medicine at the University of KwaZulu-Natal (UKZN). Our trauma centre is headed by a full-time professor of surgery (DLC) and has three other full-time faculties, all of whom are fellowship trained subspecialists in trauma surgery. It provides undergraduate, postgraduate specialist and subspecialist fellowship training in trauma surgery for both local and international doctors regulated by the College of Surgeons of South Africa (CSSA). The PMTS provides definitive and tertiary level trauma care that covers a total catchment population of over 4.5 million. Due to the extremely high incidence of interpersonal violence, gang related and other criminal activities rampant throughout the province, penetrating trauma is exceedingly common and comprises a significant workload at our trauma centre.

\section{The study}

A retrospective review was undertaken using our electronic regional trauma registry, known as the hybrid electronic medical record (HEMR), which was first established in 2012. This is a comprehensive regional trauma data bank that contains the detailed admission and hospital clinical record of every trauma patient who was treated at our institution. The establishment of HEMR has been described elsewhere in the literature. All patients admitted to PMTS over the five-year period December 2012 - December 2018 were reviewed. The date and time of admission for each patient was analysed. The lunar phase of each admission date was interrogated based on the lunar data from the Johannesburg Observatory. Each admission date was classified as either 'full moon date' (FM) or 'non-full moon date' (NFM). The basic demographics were reviewed, including gender and age. A further review was conducted based on the different mechanisms of injury.

\section{Statistical analysis}

Statistical analysis was performed using the chi-square test for categorical variables and two-sided Fisher's exact test for expected cell count less than five. Independent $t$-test and Mann-Whitney U test were used for continuous variables. For normally distributed data, the mean and standard deviation (SD) were calculated. For not normally distributed data, the median and interquartile range (IQR) were reported. A value of $p<0.05$ was considered statistically significant. All statistical analyses were performed using Statistical Package for the Social Sciences $\left(\right.$ SPSS $^{\circledR}$, Version 22, IBM Corporation, Armonk, New York).

\section{Results}

\section{Overview}

During the five-year study period, a total of 8722 cases were admitted to PMTS. Eighty-three per cent (7 242/8 722) were male and the mean age was 29 years. The total number of days during the study period was 1953,66 of which were FM days and 1887 were NFM days. There was no significant difference between the gender and the mean age of those who were admitted on FM days or NFM days. The mean number of admissions per day on FM days compared with NFM days was not significant (4.1 vs $4.5, p=0.583$ ) (Table I).

\section{Full moon vs non-full moon days}

A total of 3332 cases of penetrating trauma were admitted during the study period. This constituted 42\% (113/271) of admission on FM days and 38\% (3 219) on NFM days, which was not statistically significant $(p=0.229)$. Subgroup analysis did not demonstrate any significant difference between the number of stab wounds - 28\% (77/113) vs $25 \%$ (2 124/3 219) - or gunshot wounds - 13\% (16/113) vs $12 \%$ (990/3 219) - between FM and NFM days (Table II).

\section{Discussion}

The perception of full moon correlating to admission volume in ED has long been recognised worldwide.,2,7 There have been numerous studies interrogating the relationship between lunar phase and human behaviour. ${ }^{2,6,7}$ These include a wide range of phenomena such as homicide, suicide, violent crime and road traffic accidents. ${ }^{6-9}$ This remains somewhat controversial due to the different methodologies, definitions, and the lack of control of confounding variables in many studies. ${ }^{6-8}$ In a study by Calver et al., it was noted that violent and acute behavioural disturbance manifested more commonly during the full moon. ${ }^{9}$ However, in a large retrospective study of 1444 cases by Coates et al. at a level one trauma centre in Pittsburgh, no correlation was noted. ${ }^{6}$ In particular, there was no significant difference between

\begin{tabular}{lccc} 
Table I & & & \\
\hline & Full moon days & Non-full moon days & $p$-value \\
\hline Total days & 66 & 1887 & - \\
Total trauma admissions & 271 & 8451 & - \\
Mean trauma admissions per day & 4.106 & 4.478 & 0.583 \\
Demographics & & & \\
\hline Female & $49(18.1 \%)$ & $1431(16.9 \%)$ & 0.62 \\
Male & $222(81.9 \%)$ & $7020(83.1 \%)$ & 0.679 \\
Mean age (SD) & $29.29(14.66)$ & $29.59(14.48)$ & 0.738 \\
Mean ISS (SD) & $11.33(7.78)$ & $10.08(8.68)$ & 0.041 \\
ICU admissions & $32(11.8 \%)$ & $849(10.0 \%)$ & 0.34 \\
Mean ICU stay (SD) & $3.53(5.08)$ & $3.93(6.32)$ & 0.699 \\
Mortality & $12(4.4 \%)$ & $384(4.5 \%)$ & 0.822
\end{tabular}


Table II

\begin{tabular}{lccc}
\hline Trauma mechanism & Full moon days & Non-full moon days & $p$-value \\
\hline Blunt trauma & $153(56.5 \%)$ & $4874(57.7 \%)$ & 0.69 \\
Penetrating trauma & $113(41.7 \%)$ & $3219(38.1 \%)$ & 0.229 \\
Blunt trauma subtypes* & & & 0.763 \\
\hline Assault & $54(19.9 \%)$ & $1622(19.2 \%)$ & 0.636 \\
Road traffic accidents & $66(24.4 \%)$ & $2166(25.6 \%)$ & 0.722 \\
Accidental fall & $10(3.7 \%)$ & $352(4.2 \%)$ & 0.221 \\
Penetrating trauma subtypes* & & \\
\hline Stab wounds & $77(28.4 \%)$ & $2124(25.1 \%)$ & 0.43 \\
Gun shots & $36(13.3 \%)$ & $990(11.7 \%)$ &
\end{tabular}

* - Other subtypes are not shown on this analysis due to very small sample size

FM and NFM days regarding violent trauma admissions (assaults, gunshot wounds, and stab wounds). While the notion of full moon correlating to the admission volume is regarded by some as merely one of the many folklores in ED, a study by Danzl demonstrated that $80 \%$ of ED nurses and $64 \%$ of the ED physicians believe that the moon affects patients. Furthermore, a differential pay rise was considered warranted by $92 \%$ of ED nurses due to the perceived increase in workload and stress level.?

South Africa has a notorious international reputation for the level of civilian violence that is described as one of the highest outside countries not at war. ${ }^{10}$ This 'malignant epidemic' consumes significant resources of the overburdened and chronically underfunded health system. ${ }^{1,9,11}$ Understanding the potential factors that may influence the workload does have direct implications for resource planning. Milford et al. from Groote Schuur Hospital, Cape Town, noted correlations between temporal factors and weather variables on motor vehicle collisions and interpersonal violence. ${ }^{13}$ Other studies from South Africa reported a difference in the number of emergency department visits for traumatic injury in relation to major sporting events. ${ }^{13-15}$

Surprisingly, the phenomenon of full moon has never been studied in South Africa. To our knowledge, this was the first and only study from South Africa that also focuses exclusively on trauma admissions in relation to lunar cycle. Although not formally interrogated in this study, at the author's institution (PMTS) there appears to be a pervasive notion that such correlations exist, and informal discussion on differential pay has frequently been raised. We have demonstrated that there was no correlation between the full moon and total admission volume. Neither does full moon have any effect on admission volume for penetrating trauma.

\section{Conclusion}

The correlation between the full moon and trauma admission volume is unfounded in our setting. The perpetuating notion that 'it must be full moon tonight' is likely to be an urban myth with no scientific evidence for such a claim. Further studies from other centres within South Africa may provide a more comprehensive view.

\section{Conflict of interest}

The authors declare no conflict of interest.

\section{Funding source}

None.

\section{Ethical approval}

Ethical approval for the maintenance of our registry and for this study was formally approved by the Biomedical Research Ethics Committee of the University of KwaZuluNatal (Reference number: BCA 207/09 and BCA 221/13).

\section{ORCID}

VY Kong (iD https://orcid.org/0000-0003-2291-2572

AA Keizer (iD https://orcid.org/0000-0001-9902-3023

MM Donovan (iD https://orcid.org/0000-0003-3908-9076

RD Weale (iD https://orcid.org/0000-0001-9296-527X

NS Rajaretnam (iD https://orcid.org/0000-0001-9809-6896

JL Bruce (iD https://orcid.org/0000-0001-8666-4104

A Elsabagh (iD https://orcid.org/0000-0001-9887-8476

DL Clarke (iD https://orcid.org/0000-0002-8467-1455

\section{REFERENCES}

1. Muckart DJ. Trauma, the malignant epidemic. S Afr Med J. 1991 Jan 19;79(2):93-5. Available from: https://www.ncbi. nlm.nih.gov/pubmed/1989097.

2. Thompson DA, Adams SL. The full moon and ED patient volumes: unearthing a myth. Am J Emerg Med. 1996 Mar; 14(2):161-4. Available from: https://www.ncbi.nlm.nih.gov/ pubmed/8924138.

3. Lieber AL. Human aggression and the lunar synodic cycle. J Clin Psychiatry. 1978 May;39(5):385-92. Available from: https://pubmed.ncbi.nlm.nih.gov/641019/.

4. Templer DI, Veleber DM, Bronner RK. Geophysical variables and behaviour: VI. Lunar phase and accident injuries - a difference between night and day. Percept Mot Skills. 1982 Aug;55(1):280-2.

5. Lebowski K. Why do we still believe in 'lunacy' during a full moon? Discover Magazine [Internet]. 2019. Available from: https://www.discovermagazine.com/mind/why-do-we-stillbelieve-in-lunacy-during-a-full-moon. Accessed 11 Feb 2021.

6. Coates W, Jehle D, Cottington E. Trauma and the full moon: a waning theory. Ann Emerg Med. 1989 Jul;18(7):763-5. Available from: https://www.ncbi.nlm.nih.gov/pubmed/2735 596.

7. Danzl DF. Lunacy. J Emerg Med. 1987;5(2):91-5. Available from: https://www.ncbi.nlm.nih.gov/pubmed/3584923. 
8. Iosif A, Ballon B. Bad moon rising: the persistent belief in lunar connections to madness. CMAJ. 2005;173:1498-500. Available from: https:/www.ncbi.nlm.nih.gov/pmc/articles/ PMC1316181/.

9. Calver LA, Stokes BJ, Isbister GK. The dark side of the moon. Med J Aust. 2009;191(11):692-4. Available from: https:// www.ncbi.nlm.nih.gov/pubmed/20028313.

10. Lester D, Brockopp GW, Priebe K. Association between a full moon and completed suicide. Psychol Reports. 1969;25:598. Available from: https://www.ncbi.nlm.nih.gov/ pubmed/5367144.

11. Boffard KD. Trauma - the malignant epidemic. JCME. 2004;22(7):368. Available from: https://www.ncbi.nlm.nih. gov/pubmed/12432804.

12. Donovan MM, Kong VY, Bruce JL, et al. The hybrid electronic medical registry allows benchmarking of quality of trauma care: a five-year temporal overview of the trauma burden at a major trauma centre in South Africa. World J Surg. 2019
Apr;43(4):1014-21. Available from: https://www.ncbi.nlm. nih.gov/pubmed/30564923.

13. Milford KL, Navsaria PH, Nicol AJ, Edu S. Trauma unit attendance - is there a relationship with weather, sporting events and week/month-end times? An audit at an urban tertiary trauma unit in Cape Town. S Afr J Surg. 2016 Nov;54(4):22-7. Available from: https://pubmed.ncbi.nlm. nih.gov/28272852/

14. Zroback C, Levin D, Manlhiot C, et al. Impact of the 2010 FIFA (Federation Internationale de Football Association) World Cup on Pediatric Injury and Mortality in Cape Town, South Africa. J Pediatr. 2014;164(2):327-31. Available from: https://pubmed.ncbi.nlm.nih.gov/24252783/.

15. Nicol A, Knowlton LM, Schuurman N, et al. Trauma surveillance in Cape Town, South Africa - an analysis of 9236 consecutive trauma centre admissions. JAMA Surg. 2014;149(6):549-56. Available from: https://pubmed.ncbi. nlm.nih.gov/24789507/. 